\title{
Lumping versus splitting in meta-analysis
}

Mattias Brunström , Umeå University, Umeå, Sweden Figure 1a

Primary prevention Coronary artery disease Heart failure

One of the most important aspects in the design of systematic reviews and meta-analyses is the eligibility criteria for individual trials. In the previous issue of Hypertension News, we argued that too broad eligibility criteria leads to inclusion of trials with very different characteristics, and that the combination of such trials in meta-analyses may hide important differences in results. ${ }^{1}$ On the other hand, as argued by Professor Nadia Khan, too narrow eligibility criteria may lead to the inclusion of too few trials, impairing the statistical power to make conclusions about treatment effect. ${ }^{2}$

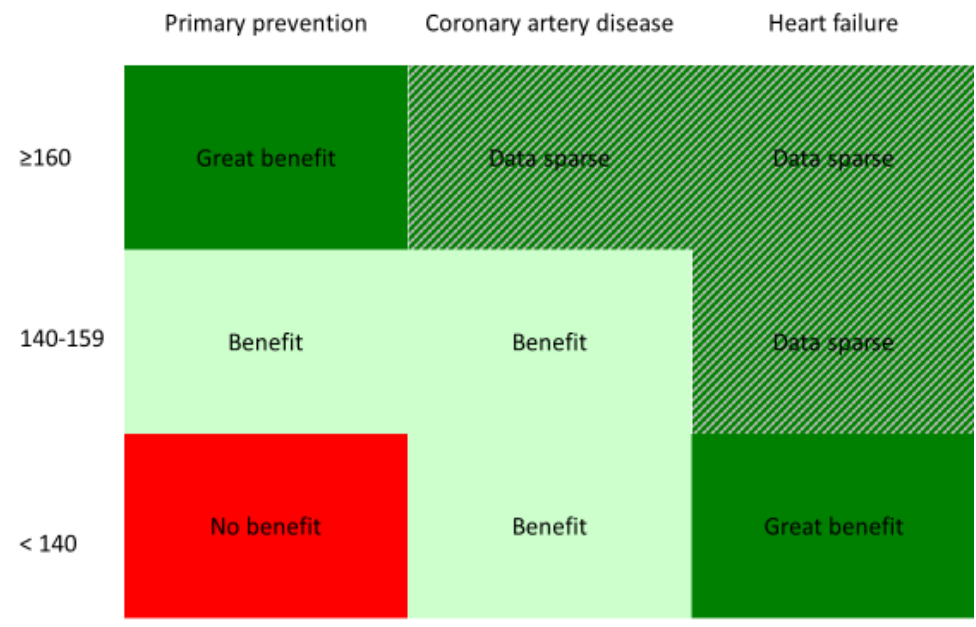

Figure 1 illustrates how lumping versus splitting affects the results of meta-analyses assessing the effect of antihypertensive treatment at different blood pressure levels. If trials are grouped by co-morbidities, separating primary preventive patients from those with established coronary artery disease and heart failure, the primary preventive effect of blood pressure lowering is attenuated at lower blood pressure levels with no effect if systolic blood pressure is below $140 \mathrm{~mm} \mathrm{Hg}$ (Fig 1a). ${ }^{3,4}$ Because treatment is beneficial in coronary artery disease and highly beneficial in heart failure, lumping trials across co-morbidities results in the appearance of an overall beneficial effect in the lowest blood pressure category (Figure $1 b) .^{5-8}$

Which one of these analytical approaches is more sensible? That depends on whether one thinks that treatment effects ought to be similar in primary prevention, established coronary artery disease and heart failure. If it is not beyond reasonable doubt that effects may differ, trials with different patient co-morbidities should be analyzed separately. This decision, which should be based on pathophysiological and pharmacological knowledge, cannot be substituted by tests for interaction once trials have been combined.

Mattias Brunström - mattias.brunstrom@umu.se

\section{References}

1. Brunström M, Carlberg B. Should All Studies Swim in the Same Pool? Hypertension News 2019; doi:10.30824/1903-8

Figure 1b

All trials combined
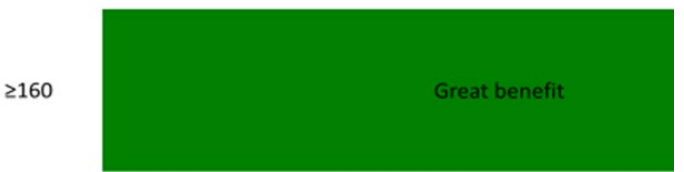

140-159

Benefit

Benefit

2. Khan N. The Devil is in the Details. Hypertension News 2019; doi:10.30824/1903-8

3. Thomopoulos C, Parati G, Zanchetti A. Effects of blood-pressure-lowering treatment on outcome incidence. 12. Effects in individuals with high-normal and normal blood pressure: overview and meta-analyses of randomized trials. $J$ Hypertens 2017; 35(11): 2150-60.

4. Brunström M, Carlberg B. Association of Blood Pressure Lowering With Mortality and Cardiovascular Disease Across Blood Pressure Levels: A Systematic Review and Meta-analysis. JAMA Intern Med 2018; 178(1): 28-36.

5. Law MR, Morris JK, Wald NJ. Use of blood pressure lowering drugs in the prevention of cardiovascular disease: meta-analysis of 147 randomised trials in the context of expectations from prospective epidemiological studies. British Medical Journal 2009; 338: 34.

6. Thompson AM, Hu TA, Eshelbrenner CL, et al. Antihypertensive Treatment and Secondary Prevention of Cardiovascular Disease Events Among Persons Without Hypertension A Meta-analysis. Jama-Journal of the American Medical Association 2011; 305(9): 913-22.

7. Ettehad D, Emdin CA, Kiran A, et al. Blood pressure lowering for prevention of cardiovascular disease and death: a systematic review and meta-analysis. Lancet 2016; 387(10022): 957-67.

8. Bundy JD, Li C, Stuchlik P, et al. Systolic Blood Pressure Reduction and Risk of Cardiovascular Disease and Mortality: A Systematic Review and Network Meta-analysis. JAMA Cardiol 2017; 2(7): 775-81. 